\title{
GEOMORPHOLOGIC METHODS FOR ESTIMATING THE FLOOD HAZARDS IN MOUNTAIN CATCHMENTS
}

\author{
Valentin NIKOLOV
}

\begin{abstract}
This article presents the possibilities for implementation of the geomorphologic methods in estimation of the morphometric characteristics and relief dismemberment in flood hazard analysis for the Malki Iskar and Suha Reka river catchment above the town of Etropole. The results shown in the maps of the vertical and horizontal relief dismemberment in GIS exhibit a very high degree of conformity between the torrential river sections and the regions with high values of horizontal and/or vertical relief dismemberment.
\end{abstract}

Keywords: Geomorphology, erosion, flood, valleys, slopes.

\section{Boundaries of the Region}

The upper part of the Malki Iskar river basin, which is the object of investigation in this study, is formed along the northern slopes of the Etropole ridge of the West Stara Planina Mountain. In geomorphologic respect it is part of the Stara Planina chainblock morphostructural zone. This first-order morphostructural unit on the territory of Bulgaria is part of the Alpine-Himalaya orogenic belt. The northern and the southern boundaries of the morphostructure are tectonically determined.

The northern boundary with the Fore-Balkan is outlined by a number of longitudinally developed valleys, parts of valleys, valley extensions or structural-denudation lowerings, marking the so-called Stara Planina frontline (a fault system). From the Botevgrad kettle to the east it climbs over the low Lopatna saddle and crosses the Etropole valley extension of the Malki Iskar River.

The southern boundary of the Stara Planina Mountain is determined by the faults, grouped in the Sub-Balkan fault zone, and is clearly and sharply outlined. It is marked by the steep ending of the southern slopes of the Zlatitsa-Pirdop kettle, a part 
of the Sub-Balkan fields. The Stara Planina Mountain ridge designates the main watershed on the Balkan Peninsula.

The boundary of the area to the north, drawn from the Malki Iskar river valley to the north of the town of Etropole, follows to the east the sub-equatorial ridge of the Chukata peak $(978.4 \mathrm{~m})$, passes to SE through the Raleva mound $(1060.3 \mathrm{~m})$ and the Padeshki peak $(993.0 \mathrm{~m})$. From here it continues along the watershed ridge between the Ribaritsa and Padesh villages and the Suhia Raven karst plateau (1048.6 m). It reaches to the south via the massif of the Strazhata peak $(1528 \mathrm{~m})$ the main ridge of the Zlatitsa-Teteven branch of the Stara Planina Mountain near the Kurduna peak $(1822.2 \mathrm{~m})$. This is the highest elevation within the range of the Malki Iskar river basin. From here the boundary follows to S-SW the main Stara Planina ridge across the Kapalu peak (1622.6 m) to the Kashana saddle, the highest point of the Zlatitsa pass. To the west, the boundary of the catchment basin follows the ridge across the Murgana peak (1638.6), the Chelopeshka Baba peak (1721.6 m) and reaches the massif of the highest peak of the Etropole Mountain - the Govedarnika or Maragidia peak $(1789.8 \mathrm{~m})$. From here the watershed ridge follows to the NW the Baba peak $(1787.2 \mathrm{~m})$, the Etropole pass $(1396.1 \mathrm{~m})$ and the Zvezdets peak $(1654.8 \mathrm{~m})$. From the massif the basin boundary follows the ridge to N-NW across the Golemia Elak (1502.2 m) and Malkia Elak peaks (1414.4 m) to the Rudinata locality. From there the watershed ridge follows to NE across the Manyakov Kamik (1439.2 m), Chuchul Mogila (1351.6 m), to the east the Chervena Voda (1256.2 m), Visokata Mogila (1037.6 m) and Vishineto (752.3 m) peaks and reaches the Malki Iskar river valley.

Within these boundaries the area of the investigated basin is $196 \mathrm{~km}^{2}$. It has an irregular oval shape and coordinates to the west $-23^{\circ} .88905 \mathrm{E}$ longitude, to the north $-420.871339 \mathrm{~N}$ latitude, and to the south $-42^{\circ} .803799 \mathrm{~N}$ latitude (Figure 1).

The main water artery in the studied basin is the Malki Iskar River. It takes its source from the Kashana saddle and flows almost in sub-meridional direction to the north. The more important of its initial tributaries are the Kozi Dol, Malki Kozi Dol, Radin Dol, Negurshtitsa, Staykov Dol, Danchov Dol and Dzhurin Dol rivers. The biggest left tributary in the investigated area is the Suha Reka River and its effluents - the Ravna and Kobilya rivers.

\section{Initial Information}

Geological and Geomorphologic Data and Characteristics of the Territory of the Malki Iskar River Basin

The studied region is rather diverse in geological-tectonic respect and for this reason the geological and geomorphologic structure of its territory is rather complex. It is built of pre-Paleozoic metamorphites; overthrusted from the south Paleozoic grani- 


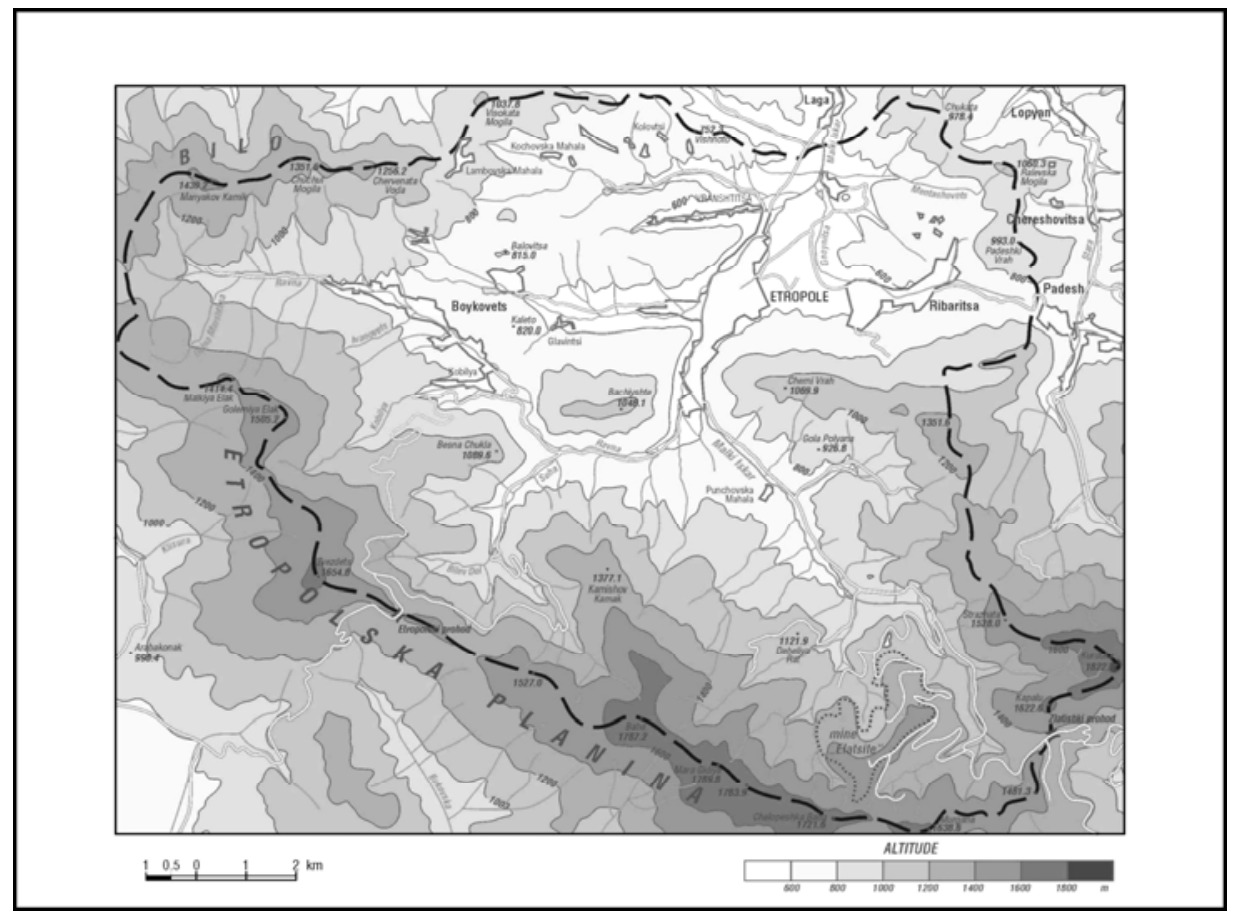

Figure 1: Studied Area.

toids, Mesozoic sediments; Upper Cretaceous volcanites and volcanogenic-sedimentary rocks and Neogene and contemporary deposits. The active tectonic movements with contrast signs of movement during the Alpine stage and later contributed to the diverse and expressive relief. These contrasts in orography exert substantial effect on the development of the erosion processes, the orientation and character of the midstream network as well as on the formation of the so-called "orographic" effect on the microclimate of the region. The basic local morphostructures in the region of the Malki Iskar river basin that have been formed later on may be distinguished. They build the morphostructure of the Etropole Stara Planina Mt. (Zlatitsa - Teteven ridge). It comprises the Bilo Mt., the Baychishte and Cherni Vrah ridges and the Etropole kettle. The Etropole Formation (argillites and sandstones) and the Neshkovska and Cherni Osam Formations (flysch and sandstones) with Jurassic and Lower Cretaceous age are found in the Etropole valley extension (formed in the kettle morphostructure). Pleistocene and contemporary alluvial materials are developed on top of these formations. 


\section{Geomorphology Development}

The relief of the Etropole Stara Planina Mt. is the result of the activity and complex interaction of the internal and external Earth forces, displayed mainly during the Late Alpine and the Neotectonic stages of the Earth's crust development. According to its genesis, the relief is structural-denudation one with intensive manifestation of contemporary erosion processes. The relief of the Earth's surface may be represented as a field of random variable quantities expressing its altitude, depth and dismemberment, density of dismemberment, slope inclination, etc. ${ }^{1}$ The formation of the mountain as a positive orographic unit started as early as in the end of the Paleogene. However, regardless of its chain character, the mountain development was strongly differentiated. The oldest denudation surface with highest rising is of Paleogene-Lower Miocene age, its traces being observed along the main ridge of the Etropole Stara Palnina Mt. at an average altitude of 1500-1800 m. The coarse basic features of the relief were formed during the Neogene, which lasted about 30 million years. Its details were formed during the Plio-Pleistocene with duration of 2-3 million years. This occurred also under conditions of ascending tectonic movements. The Pleistocene development of the Stara Planina Mt. was also with differentiated character determined mainly by its block structure. In the northern steep slope river terraces are almost missing in the valleys, which is an indication for almost complete continuity of the positive component of the tectonic regime. Up to three non-flood and two flood terraces are observed within the range of the Etropole valley extension.

Other relief forms were shaped in connection with the stage geomorphologic development, the particular geological structure and tectonics. A typical example in this respect is the formed karst - in the massif of the Baychishte-Cherni Vrah chain. Surface karst forms are developed here on the top parts of the ridge - pot-holes, hollows and karren fields. Caves and cave niches are observed along the slopes. A magnificent waterfall and beautiful travertine formations are developed in the vicinity of the Etropole "Sv. Troitsa” Monastery.

In the highest parts of the Etropole Stara Planina Mt. the frost weathering processes are manifested with especial intensity. The stone rivers and seas in the Golemia Elak massif represent similar forms. They result from the spherical weathering of the granitoids and provide rich material evidence about the rich mud streams and screerockfall processes and colluvial deposit accumulation (Figure 2).

\section{Methodology and Analysis of the Obtained Information}

The basic methods of the morphometric relief analysis were applied for the analysis of the erosion processes in the upper course of the Malki Iskar river basin (to the town of Etropole), namely - the vertical and horizontal dismemberment, the total erosion dismemberment, the midstream network inclination, the longitudinal profiles of 


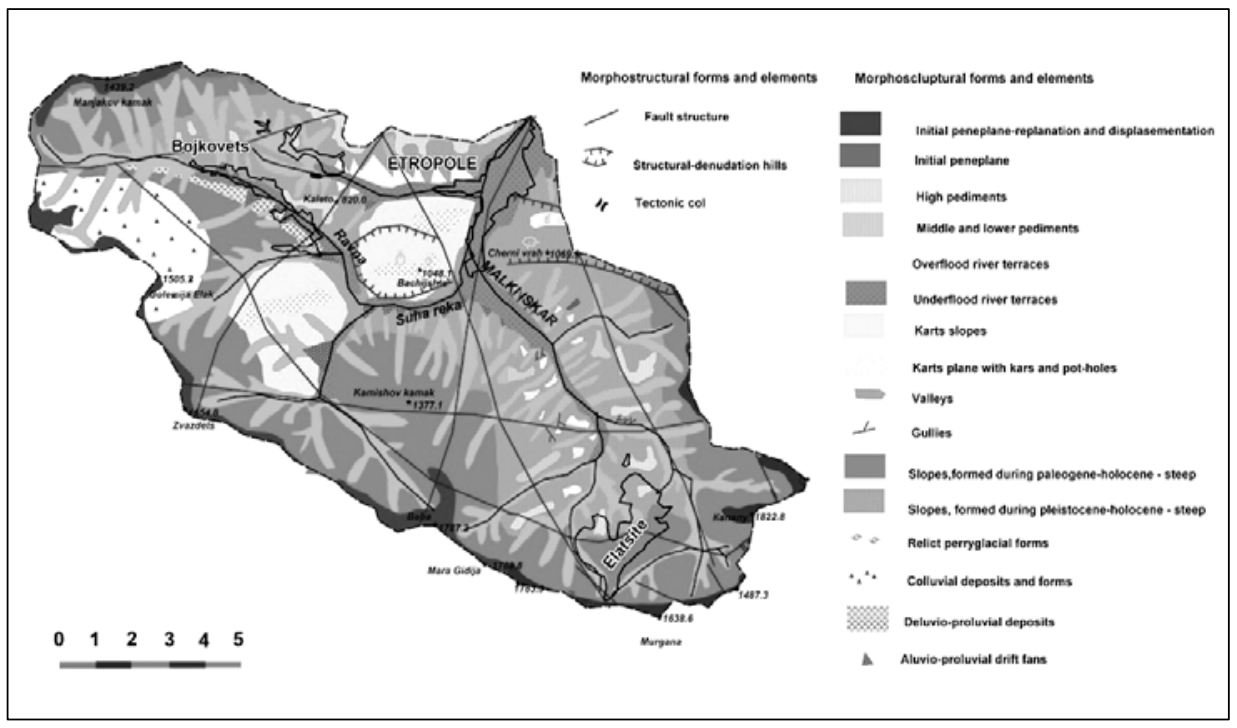

Figure 2: Geomorphology Map.

certain valleys, the ranks of the river-valley network. Topographic materials, DEM of the relief and GIS were applied for this purpose. The relief specific features of the Malki Iskar river catchment are especially well characterized by the analysis of relief morphography and morphometry. The parameters of the vertical, horizontal and total relief dismemberment were obtained from this analysis.

\section{Development of the Erosion Processes in the Malki Iskar River Basin}

The erosion network development is a natural process and may be considered by means of the general theory of denudation in mutual dependence and relation of the endogenous and exogenous processes. Water erosion is a process, during which the materials building the soil, rocks, etc., are destroyed and carried away by surface flowing water. It may be provisionally divided in three phases - destruction (erodio), transport and deposition (sedimentation) of the materials. The process intensity and single phases predominance in every single moment or part of a given basin depends on the relief characteristics, climatic and hydrologic conditions. The natural (normal) erosion is a relatively slow process in nature but depending on the above mentioned physical geographic conditions it may attain big or catastrophic dimensions. Each river system possesses individual specific features, determined by the water circulation in nature, the geological structure of the territory and the relief and landscape specificities of the basin. The basic parameters of a given river system are hydrographic, hydrologic and morphometric. The hydrologic parameters characterize the 
multiannual, annual, monthly and daily water runoff. The morphometric parameters characterize statistically with sufficient objectiveness the relief of the river valleys and basins. Morphologically the river-valley network is divided in drainage and transit one depending on the character of the erosion-denudation processes occurring in a given basin. The catchment basin represents a part of the Earth's surface, on which the runoff towards the main river is formed via the tributary drainage network. It is separated from other elementary or bigger watershed basins by watersheds passing along the highest ridges outlining the respective basins. The basin of the upper course of the Malki Iskar river has a predominantly drainage character, as a typical mountain basin, but in single sections with low inclinations of the longitudinal profile (in the valley extensions and the kettle lowering of the town of Etropole) accumulation of deposits is observed. The development of the midstream network, in which a big part of the surface runoff is concentrated, along the steep slope sections of the Etropole Mt. exhibits intensive vertical (deep) and lateral erosion. The processes are especially well manifested in the case of weakly bound or strongly denudated and tectonically processed rocks. Depending on the geomorphologic features of the investigated territory, the single watersheds possess different morphometric characteristics. The shape of the single elementary basins and of the main river basin is typical for mountains and fore-mountain pedestals and is with a dendrite-like and grid-like pattern, favorable for collecting a great part of the precipitation and ground and surface runoff in the midstream network of the Malki Iskar river basin.

\section{Morphometry of the Malki Iskar River Basin}

\section{Ranks of the River-valley (Midstream) Network}

The ranking of the component midstreams of the main river shows that they are basically from the I, II and III rank, which is typical for mountain relief according to the scheme of Horton ${ }^{2}$ that has been systematized and modified according to FilosofovStrahler (1992). ${ }^{3}$ The ranked midstreams correspond to the same rank of basins (according to Rice). ${ }^{4}$ The I ${ }^{\text {st }}$-rank valleys represent elementary valley systems, which have no tributaries with formed beds and possess predominant lateral (deep) erosion. The second rank valleys are formed by merging two first rank valleys. The third rank valleys are formed by merging two second rank valleys. They are characterized by relative equilibrium between deep and lateral erosion, but the inclination is still too big and the water quantities forming the flows have good transportability. The Suha Reka River and the Malki Iskar River in the middle course have a rank IV after the town of Etropole. Thick sediments are deposited in the local erosion bases, which are products of periodic torrential manifestations. The lack of medium and high nonflood terraces shows that the valley network is young. This is a criterion that the occurring processes displayed in the basin will be mainly denudation and erosion ones, 


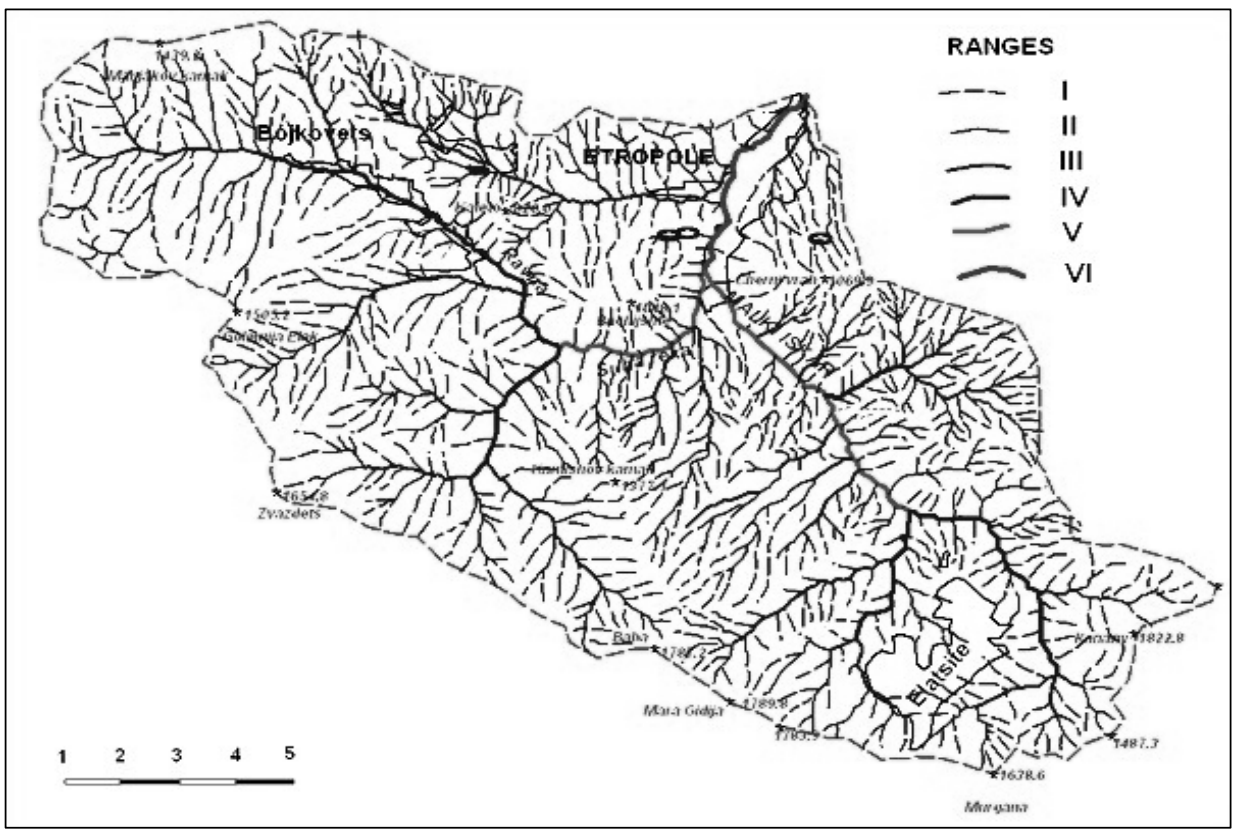

Figure 3: Ranks of the River-valley Network.

thus sometimes exhibiting dangerous character in combination with the physical geographic conditions and the presence of anthropogenic interference in the high parts of the catchments (Figure 3).

The dimensions and shape of the river valleys are related to their rank. The first rank ones have narrow or short valleys in the foot of the mountain ridges or represent transitional forms from surface to linear erosion of the gorge or ravine type. The transition between such temporary streams into permanent ones depends strongly on the hydroclimatic and less on the geological-geomorphologic conditions. The latter exert effect mainly on their length. Recently the development of such midstream types is more influenced by the effect of the anthropogenic factor (road construction, deforestation, agriculture).

\section{Vertical Dismemberment}

The vertical relief dismemberment shows in fact the depth of incision of the midstream network, its formation being related to the erosion-denudation activity of surface flowing water. The field of vertical relief dismemberment is highly informative with respect to morphostructure. It represents the relief plasticity mainly as a function of the differences in the type and sign of vertical deformations. Morphometrically, it is calculated by means of the difference between the highest and the lowest point in a 
unit area of the studied watershed using the formula $Q_{v}=\Delta H / P$, where $\Delta H$ is the difference between the height extremums in the elementary square $\left(\mathrm{km}^{2}\right)$, divided by its area. The combined analysis of the map of vertical relief dismemberment and the real inclinations shows that the areas with high vertical dismemberment values outlined by the isoamplitudes almost coincide with those with predominant high inclination values, where high inclination values of the order of $25^{\circ}-30^{\circ}$ and more than $30^{\circ}$ are prevalent. A coincidence is also observed in the direction of spreading of these areas (Figure 4).

They have good correlation with the established fault disturbances and boundaries of the morphostructural units according to geological and tectonic data. Almost complete coincidence is observed for the areas delineated by isoamplitudes with low values and small inclinations. The low values are typical for the watersheds and ridges as well as for valley extensions, and the medium and high values are observed along the slopes of high mountain ridges. The following conclusions may be drawn from the performed analysis:

- The degree of vertical dismemberment is a parameter for the intensity of the morphogenetic processes and active tectonic regime, the erosion process fluctuations and rock stability.

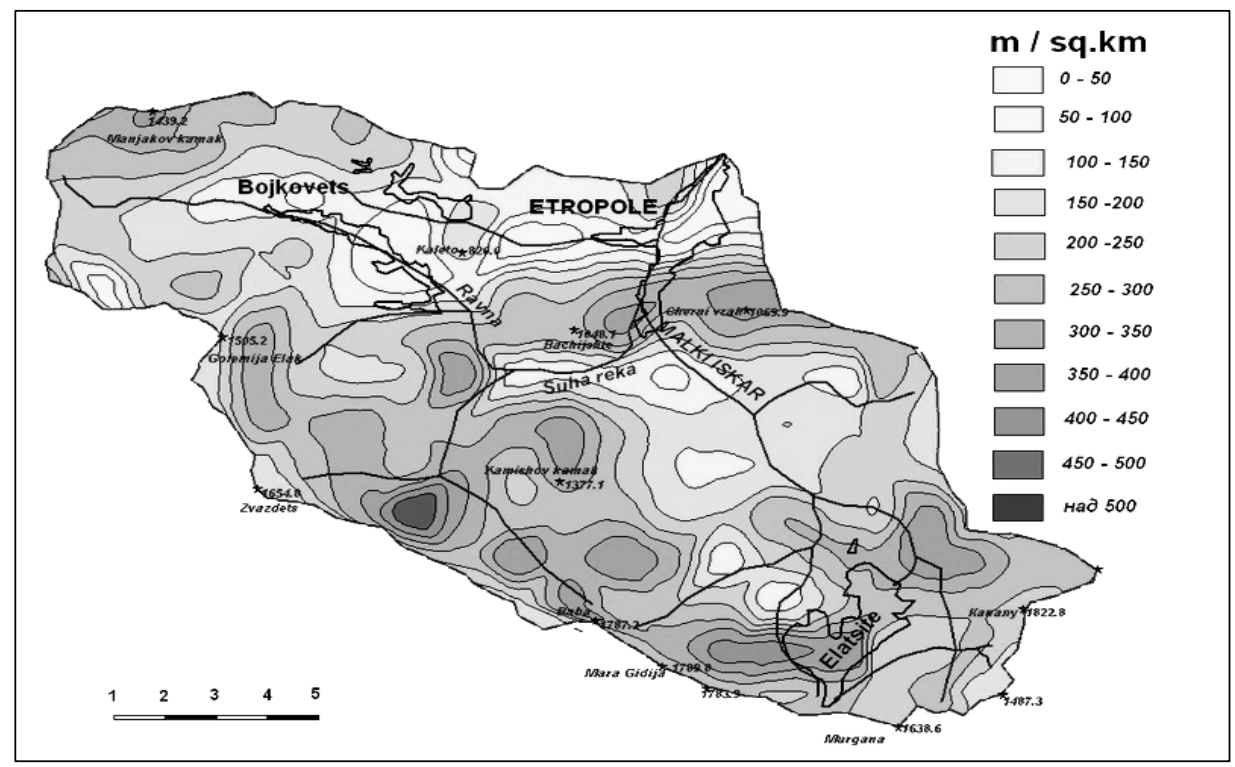

Figure 4: Vertical Dismemberment. 
- The places with high values of vertical dismemberment and slope inclination are characterized by generation of high runoff velocities and high probability of torrential events.

- The places with low values of vertical dismemberment are characterized by the formation of local erosion bases and possibilities for accumulation of the transported by eventual torrents materials.

\section{Horizontal Dismemberment}

The field of horizontal relief dismemberment (density of erosion dismemberment) represents the plasticity of relief mainly as a function of the sculptural (exogenous) processes and the density of the linear erosion relief forms. It is expressed as the sum of midstream length per unit area according to the formula $Q_{h}=\sum L / P$. The low and medium values of the density of dismemberment are typical for the alluvial bottoms and flat ridge parts. Recently, the anthropogenic impact on the basin territory plays an important role for increasing the midstream network density, for example, the uncontrolled tree cutting and construction of non-stabilized temporary forest roads, along which road gullies develop, lead to disturbances in the equilibrium of rock complexes along valley slopes. The values vary within a broad range for the investigated region of the upper course of the Malki Iskar river catchment basin (Figure 5).

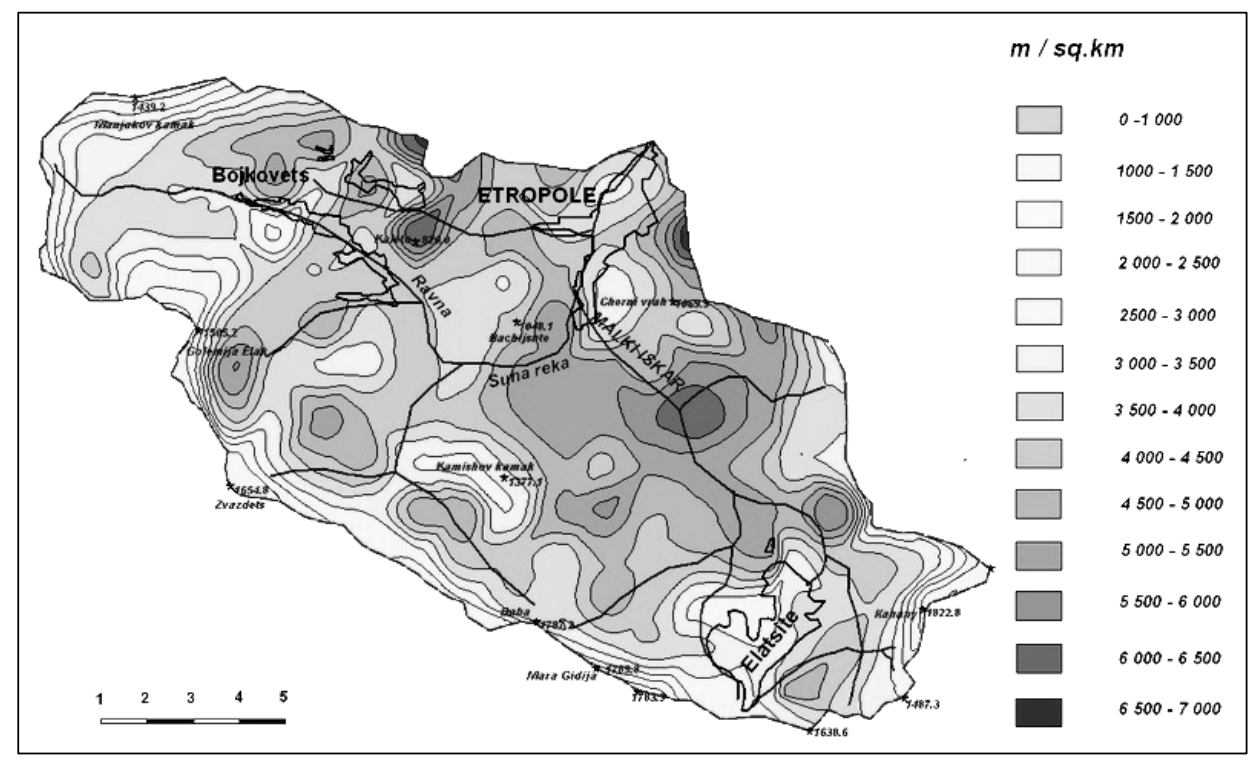

Figure 5: Horizontal Dismemberment. 
The dismemberment values for the watersheds are low and medium and vary from almost zero dismemberment to $2500 \mathrm{~m} / \mathrm{km}^{2}$. High and extreme values of horizontal dismemberment are observed along the Stara Planina Mt. foot in the Suha Reka river catchment, along the middle and lower course of the Malki Iskar river, to the south and north of the town of Etropole, in the northern catchment part of the area. The isodase tenor here exceeds $4500 \mathrm{~m} / \mathrm{km}^{2}$ and reaches up to $6000 \mathrm{~m} / \mathrm{km}^{2}$ at some places. These maximums mark valley extensions and local erosion bases and catchments at many places. Under circumstances with unfavorable combination of a number of natural factors they are a prerequisite for accumulating large amounts of water and mud-stone masses (Seli) and provoking disastrous torrents. Some of these anomalous sections are developed along the length of fault zones. The rocks building the Earth's crust in these sections are strongly disintegrated and very susceptible to erosion-denudation processes, which has contributed to the intensive development of the rivervalley and gully-gorge networks as well as to the accumulation of many loose and crushed materials (deluvial-proluvial talus fans, stone rivers and seas). They provide abundant material for mud (seli) streams.

\section{Total Dismemberment}

It is represented by the coefficient of erosion dismemberment intensity $Q$, which is a sum of the vertical $(H)$ and horizontal $(L)$ components of the erosion processes in the natural environment.

The magnitude of the intensity coefficient of erosion relief dismemberment is considered as an objective morphometric and morphologic factor of areas subjected to various types of ecological hazards.

The determination of the intensity coefficient of erosion relief dismemberment $(Q)$ and its graphic representation in a map is made according to the following formulae: $Q=H \times L / P^{2}$, where $H$ is vertical dismemberment, $L$ - horizontal dismemberment. The obtained values are tested and reduced to the form of grade assessment of total erosion dismemberment. The scale is chosen in such a manner that it could reflect with high accuracy the specific features of the erosion processes for the territory of the basin of the upper course of the Malki Iskar river (Figure 6).

The tenor of the isolines shows that the intensity of erosion dismemberment is the highest in the foot of the main Stara Planina Mt. ridge and in the gorge sections of the Ravna, Suha and Malki Iskar rivers immediately before and after the valley extensions. Valleys of first and second rank with high erosion potential are formed in the high parts and due to the high inclination of midstreams they also exhibit high transportability of the hydrologic component. On the contrary, in the valley extensions (in the town of Etropole and the Boykovtsi village) the grade values of total dismember- 


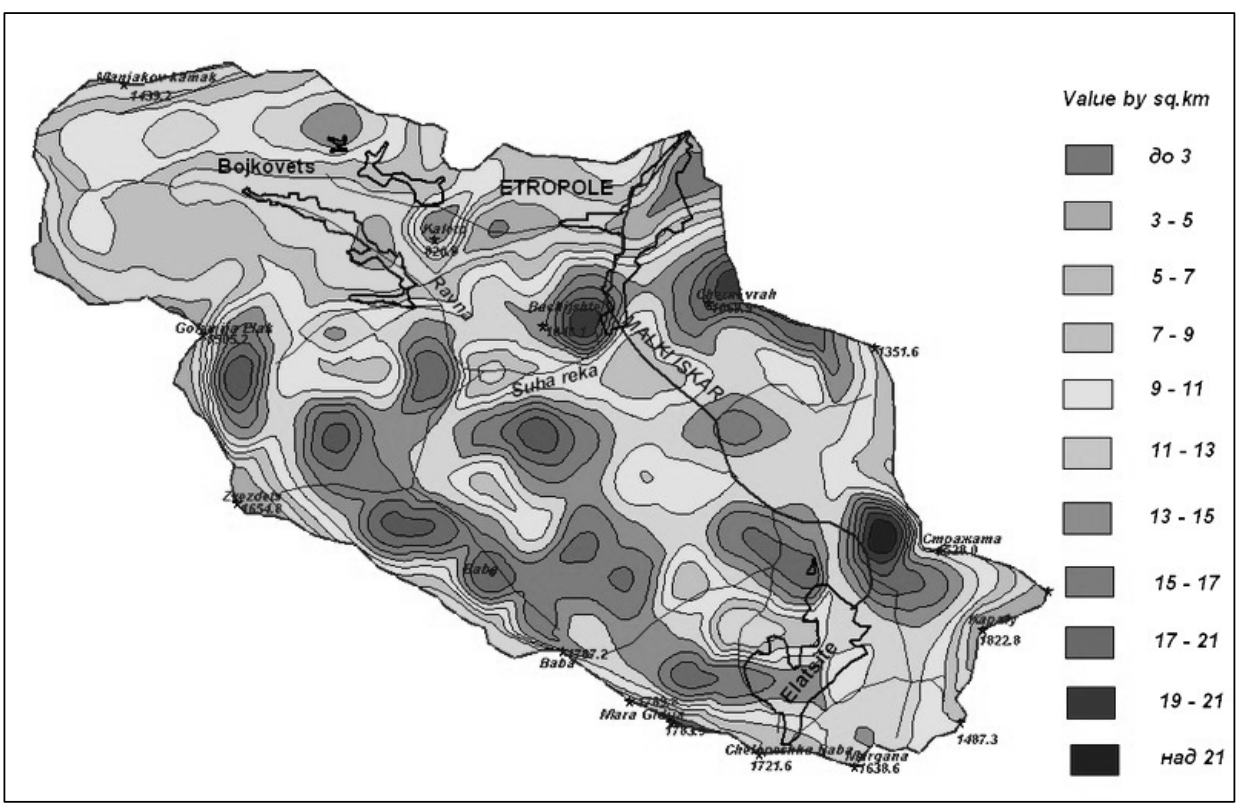

Figure 6: Total Dismemberment.

ment are the lowest. Here the erosion is very small or insignificant but the transport and especially the sedimentation are enhanced. In combination with the gorge sections of the river valleys, prerequisites are created in these local erosion bases for intensive sediment accumulation, especially during torrents and high water levels. The low localities of total erosion dismemberment in the ridge parts along the watersheds and the main ridge are predetermined by the morphology and morphography of the relief - flattened surfaces with dominating weak manifestations of planar wash-away and weathering processes with eluvium formation. Surface erosion is transformed to stream (groove) one with slope increase and to linear in subsequence, an individual river basin being developed in this manner.

Some of the most representative quantitative and qualitative characteristics of the catchment basin are the parameters of real slope inclinations as well as the longitudinal (Figure 7) and transverse profiles of the midstream network. The real inclinations of valley slopes may be considered to be a synthetic geomorphologic feature and are functions of three basic parameters - average altitude per unit area or elementary basin, absolute height of the local erosion basis and coefficient of the dependence on the area of the studied basin. The analysis of the real inclinations for the area of the Malki Iskar river basin shows the basic relationships of their distribution on this territory. The high values $\left(20^{\circ}-25^{\circ}\right)$ have broad distribution of real inclinations, values 

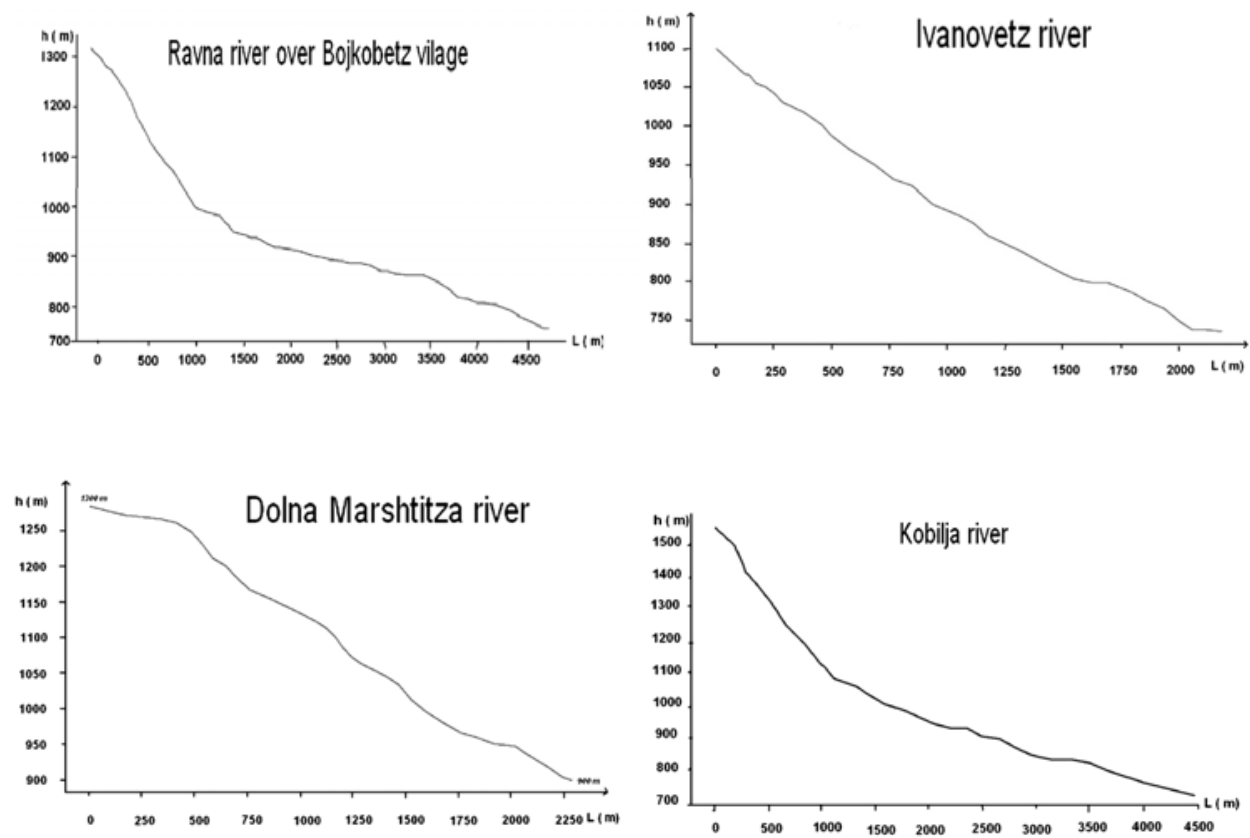

Figure 7: Longitudinal Profiles.

about and exceeding $30^{\circ}$ being also observed at some places. These are the regions of the Bachiishte ridge, the Malki Iskar river in the uppermost course and the northern foot of the main Stara Planina Mt. ridge. The areas with real inclinations from $10^{\circ}$ to $20^{\circ}$ are most widespread and they comprise the lower parts of the Stara Planina slope, the northern and northwestern valley slopes of the Ravna river, the slopes along the middle and lower course of the Suha river, the middle course of the Malki Iskar river and the northern parts of the basin. Real inclinations with low values less than $10^{\circ}$ are developed along the flattened surfaces of the watersheds and along the main Stara Planina Mt. ridge, in the valley extensions of the Ravna and Suha rivers and in the Etropole structural-denudation lowering.

An important morphometric characteristic of the relief in the Malki Iskar river catchment is the exposition of the slopes. There is a great diversity of expositions due to the isometric shape of the basin. The predominating slopes of the basic morphostructures in the region are directed to the north, south, northwest and southwest. The analysis of the valley slopes of the elementary midstreams gives an extremely variegated pattern. All possible expositions are observed here. 
An important qualitative characteristic of slope surfaces is derived from the analysis of the transverse profiles of the valleys, namely - the slope type. The three basic types for middle height mountain territories are encountered here - the convex, rectilinear and concave slope types. The first type characterizes emerging young and undeveloped valleys and erosion forms, as well as valley sections of the bigger rivers, influenced by lithological and tectonic factors. These are ravines, gullies, initial tributaries in the upper courses of the basic mainstreams. Deep erosion and highly intensive transfer of destructed material prevail here. The second type - the rectilinear forms, characterizes the middle courses of the bigger rivers. The valley slopes here are formed by the equally displayed deep and lateral erosion. Except for the erosion and material transport, deposition is also observed at some places. The concave slopes are typical for parts of the valleys, where a profile of equilibrium is formed and the leading processes are lateral erosion and deposition.

The longitudinal profiles of some rivers in the western, southern and northern parts of the catchment are analyzed. The profiles of the rivers taking their source from the main ridge and from the Manyakov Kamik massif are characterized by very steep initial sections, steep to slanting medium sections and slanting lower parts of the valleys. The tributary network from the north is characterized by almost regularly manifested slanting longitudinal profiles along the whole midstream length.

\section{Conclusions}

The analysis carried out for the territory, encompassing the Malki Iskar river basin, shows the substantial role of relief for the development of erosion processes in the region. In combination with the climatic, hydrologic and geological processes, and not on the last place - with the anthropogenic impact on nature, certain relationships may be outlined for the region of the Malki Iskar river basin about the influence of relief on the hazardous erosion processes.

- The values of the erosion relief dismemberment are indicative for the duration, strength and direction of the erosion processes, the rock base stability, as well as for the contemporary morphogenetic processes determined by the tectonic movements during the neotectonic and the contemporary stage, the relief, climatic and hydrodynamic processes. Intensive erosion is observed in the regions with high values of erosion dismemberment (vertical and total). These are mainly the regions of the northern steep slope of the main Stara Planina Mt. ridge along the massifs of the Zvezdets (1 $654.8 \mathrm{~m}$ ), Baba (1 787 m), Maragidia (1 790 m), Golemia Elak (1 585.2 m), Manyakov Kamik (1 439 m), Kamishov Kamik (1 371.1 m), Murgana (1 628 m), Kapalu (1622 m) peaks, etc. High values of relief dismemberment are observed in the massif of the Baychishte (1 $049 \mathrm{~m})$ and Cherni Vrah (1 $069.9 \mathrm{~m})$ peaks, 
where gorge sections are developed with deep incision in the valleys due to the carbonate complexes building them. The steep inclination of the midstream network in these sections of the watershed ridge slopes provides possibilities for high rates of erosion processes and frequent surface water outflows of torrential character under certain climatic and hydrologic conditions. Similar flows are the right tributaries of the Ravna river (the Ivanovets, Gorna and Dolna Marishtitsa and Kobilya rivers) and the Suha river (Varnishki Dol, Bilev Dol and Dalboki Dol rivers), which are characterized by very steep slopes and narrow deeply incised valleys and are capable of generating powerful torrents. Similar characteristics are typical for the river valleys forming the upper course of the Malki Iskar river in the foot of the Murgana, Kapalu and Strazhata peaks - of the Negarshtitsa, Ravna, Dolna and Gorna Kamenitsa rivers. Their natural morphohydrographic regime is disturbed by the "Elatsite" mine.

- Good correlation has been established between the areas with high values of vertical erosion dismemberment and predominant high values of real inclinations and the longitudinal profile of most of the midstreams in the basin.

- For similar lithological characteristics of the covering surface, the higher values of the horizontal dismemberment delineate the areas with shallowly incised erosion network, low inclinations and prevalence of accumulation over erosion. However, the denser midstream network on its side may collect bigger surface runoff during abundant precipitation and generate vast water mass amounts.

- Favorable conditions for the occurrence of hazardous torrential processes exist in the parts with alternating narrow river valley sections with high slopes (the gorges of the Ravna and Suha rivers) and valley extensions. The gorges create natural retention and afterwards - possibilities occur for swelling water masses with high erosion and transport energy.

- Thick colluvium is developed along the slopes of the Golemia Elak and Malkia Elak peaks, which affords the possibility for the formation of mud streams with large boulders in case of intensive runoff in the midstream network.

- Conditions for intensive degradation processes exist along the northern valley slope of the Ravna river, which are favorable for hazardous phenomena development - surface wash-away and ravine-gorge erosion, due to the rather unstable against denudation lithological base (aleuritic-clayey group affected by metamorphism and faulting) and to the deforestation and active road erosion. 


\section{Notes:}

1 Zhivko Galabov, "On the Application of Morphometric Analysis in Geomorphological Investigations,” Problems of Geography in Bulgaria 2 (1968): 7-37.

2 Robert E. Horton, "Erosional Development of Streams and Their Drainage Basins; Hydrophysical Approach to Quantitative Morphology,” Bulletin of the Geological Society of America 56, no. 3 (March 1945): 275-370.

3 A. Filosofov, Fundamentals of the Morphometric Method in Exploring Tectonic Structures (Saratov: Publishing House of the Saratov University, 1975), 232.

4 Roger J. Rice, Fundamentals of Geomorphology (London: New York, 1978), 574.

VALENTIN NIKOLOV has been Research Associate in the Institute of Geology, Bulgarian Academy of Sciences, since 2005. He graduated in geomorphology and cartography from Sofia University “St. Kliment Ohridski,” Department of Geology and Geography. He worked as Research Associate in the Research Institute of Mineral Resources, CRI "Geology and Geophysics" and the Institute of Geography at the Bulgarian Academy of Sciences. His research interests are the field of physical geography, geomorphology, natural hazards, and morphostructural analysis. He has more than 32 scientific publications. Address for correspondence: Institute of Geology, Bulgarian Academy of Sciences, "Acad. Georgi Bonchev” Str., bl. 23, 1113 Sofia, Bulgaria; Phone: (+359 2) 979 3616; E-mail: valnvaln@yahoo.com. 